\title{
Effects of small interfering RNAs targeting fascin on human esophageal squamous cell carcinoma cell lines
}

\author{
Cristian M Ortiz*1, Tetsuo Ito2, Yosuke Hashimoto33, Satoshi Nagayama4, Akira Iwai4, Shigeru Tsunoda4, Fumiaki Sato5, \\ Miguel Martorell' ${ }^{1}$ Jose Angel Garcia' ${ }^{1}$ Ana Perez ${ }^{1}$ and Yutaka Shimada 6
}

\begin{abstract}
Background: Fascin induces membrane protrusions and cell motility. Fascin overexpression was associated with poor prognosis, and its downregulation reduces cell motility and invasiveness in esophageal squamous cell carcinoma (ESCC). Using a stable knockdown cell line, we revealed the effect of fascin on cell growth, cell adhesion and tumor formation.

Methods: We examined whether fascin is a potential target in ESCC using in vitro and in vivo studies utilizing a specific siRNA. We established a stable transfectant with downregulated fascin from KYSE170 cell line.

Results: The fascin downregulated cell lines showed a slower growth pattern by $40.3 \%(p<0.01)$ and detachment from collagen-coated plates by $53.6 \%$ ( $p<0.01)$, compared to mock cells, suggesting that fascin plays a role in cell growth by maintaining cell adhesion to the extracellular matrix. In vivo, the tumor size was significantly smaller in the tumor with fascin knockdown cells than in mock cells by $95 \%$ at 30 days after inoculation.

Conclusions: These findings suggest that fascin overexpression plays a role in tumor growth and progression in ESCC and that cell death caused by its downregulation might be induced by cell adhesion loss. This indicates that targeting fascin pathway could be a novel therapeutic strategy for the human ESCC.
\end{abstract}

\section{Background}

Esophageal squamous cell carcinoma (ESCC) is one of the most prevalent cancers worldwide [1,2]. One of the reasons for its poor prognosis is that ESCC is difficult to diagnose at an early stage and exhibits local invasion and lymph node metastasis in its advanced stage, even at initial diagnosis [3]. The capability of tumor invasion and metastasis is the result of several sequential steps including motile properties of tumor cells to overcome cell-cell and cell-matrix adhesion and to invade the surrounding tissue [4-6].

Invasive tumor cells often show morphological changes, such as membrane protrusions as well as the loss of cell-cell adhesion and the loss of junctional communications, which probably result from rearrangements

\footnotetext{
* Correspondence: cortizv@gmail.com

1 Department of Pathology, Valencia University, Hospital General Universitario de Valencia, Avenida tres cruces №2, CP 46014, Valencia, Spain Full list of author information is available at the end of the article
}

of the cytoskeletal microfilaments by the action of actin cross-linking proteins [7-9]. Fascin is a highly conserved $55-\mathrm{kDa}$ actin bundling protein that plays an important role in the organization of several types of actin-based structures such as filopodia, lamellipodial ribs, dendrites, spikes and microvilli [10]. It was originally found in extracts of unfertilized sea urchin eggs and localized to microfilament bundles within microvilli cores and within filopodia on the surface of fertilized sea urchin eggs [11]. Fascin is normally expressed in cells inducing membrane protrusions and increased cell motility, such as neurons, glial cells and dendritic cells [12-14] or migrating cells such as endothelial cells and macrophages [14]. The fascin expression level in epithelial cells is usually low, however it is often upregulated and overexpressed in transformed cells and in several types of human neoplasm, including breast [15,16], ovary [17], skin [18], pancreas and liver [19-21], non-small cell lung carcinomas, lung carcinoids [22,23], stomach and esophageal 
squamous cell carcinoma $[18,24,25]$. We have previously reported that actin bundling protein fascin and its overexpression was related to poor prognosis, as well as that its stable knockdown reduces cell motility and invasiveness in the ESCC [26]. We have also reported that fascin immunoreactivity in gastric carcinoma was associated with lymph node metastasis [27]. In order to determine whether fascin is a potential gene target, we performed in vitro and in vivo studies. In the present study, using a stable knockdown cell line, we elucidated the role of fascin in cell growth and cell adhesion in vitro and revealed the effect of fascin knockdown on the tumor growth in the in vivo tumor formation assay. These results imply a potentially important role of fascin inhibition in the treatment of ESCC and the prevention of tumor invasion and metastasis.

\section{Methods}

\section{Cell culturing}

All human esophageal squamous carcinoma cell lines KYSE 170 parental (wild) and derivate cells (KYSE 170mock, KYSE 170F3 and KYSE 170F4) were established in our laboratory and maintained in RPMI 1640 (Life Technologies, Gaithersburg, MD) and Ham's F12 (Nissui Pharmaceutical, Tokyo, Japan) with 2\% fetal bovine serum (FBS).

\section{Western blot analysis}

Whole-cell extract lysate was prepared from $1 \times 10^{7}$ cells in a sample buffer ( $2 \%$ sodium dodecyl sulfate [SDS], $10 \%$ glycerol, $50 \mathrm{mM}$ Tris-Hcl, $\mathrm{pH}$ 6.8) at room temperature. Cell lysates were sonicated and the protein content was measured with the Bradford method using BCA Protein Assay Reagent (Pierce, Rockford, MA), after which the cell lysates were electrophoresed on a $12 \%$ polyacrylamide gel SDS page and transferred to a polyvinylidene difluoride membrane (Immobilon, Milipore, Bedford, MA) using a semidry transfer blot system (Bio-Rad, Hercules, CA). The membranes were blocked with TBS $(20 \mathrm{mM}$ Tris, $150 \mathrm{mM} \mathrm{NaCl}, \mathrm{pH}$ 7.6) containing $1 \%$ Tween 20 and $5 \%$ skimmed milk for 1 hour. The membranes were incubated overnight at $4^{\circ} \mathrm{C}$ with anti-human fascin mouse monoclonal antibody (DAKO, Osaka, Japan; diluted 1:500) or with anti-human $\beta$-actin mouse monoclonal antibody (Sigma Inc., St. Louis, MO; diluted 1:2000) as an internal control. They were washed and then incubated at room temperature for 1 hour with anti-mouse IgG-HRP (Zymed, San Francisco, CA), as a secondary antibody, and analyzed using ECL plus reagent (Amersham, Buckinghamshire, UK).

\section{Purification of total cellular mRNA and Reverse Transcription-PCR}

Total RNA was extracted from KYSE cell lines by the TRIzol reagent (Invitrogen, Carlsbad, CA) according to the manufacturer's protocols $[28,29]$. Reverse transcription of total cellular RNA was performed using a FirstStrand cDNA Synthesis Kit (Amersham, Buckinghamshire, UK). cDNA was subjected to PCR for 25 cycles of amplification using an Advantage cDNA PCR kit (Becton Dickinson Biosciences, Palo Alto, CA). Each PCR cycle consisted of a denaturation step for 1 minute at $94^{\circ} \mathrm{C}$ and an annealing step for 1 minute at $60^{\circ} \mathrm{C}$. The final extension step was carried out for 5 minutes at $72^{\circ} \mathrm{C}$. The PCR products were separated on $1.5 \%$ agarose gel and visualized by ethidium bromide staining. PCR primers used for fascin were 5'- AGGCGGCCAACGAGAGGAAC-3' as the forward primer and 5'-ACGATGATGGGGCGGTTGAT-3' as the reverse primer; and for glyceraldehydes-3phosphate dehydrogenase (G3PDH), 5'-TGGTATCGTGGAAGGACTCATGAC-3' was used as the forward primer and 5'-ATGCCAGTGAGCTTCCCGTTCAGC-3' as the corresponding reverse primer. cDNA from HeLa cells was used as a positive control for each analysis.

\section{Cell growth assay}

Cells were plated into $6 \mathrm{~cm}$ dishes $\left(2 \times 10^{4}\right.$ cells per dish $)$ at day 0 and incubated for 24 hours for sufficient cell growth. Cells were harvested with trypsin/EDTA every 48 hours for five days, and counted with a cell counter (Coulter Z1, Beckman Coulter, Fullerton, CA). To examine the effect of the suppression of fascin expression on cell growth, we compared it with the control culture in triplicate. Each experiment was repeated three times independently.

\section{Adhesion assay}

Cells were seeded into collagen-coated plates (Becton Dickinson, MA) without FBS. After 24 hours of incubation, the adherent and floating cells were counted from five randomly selected fields. The assay was repeated three times under the same conditions.

\section{Caspase inhibition}

$200 \mu \mathrm{mol} / \mathrm{L}$ Z-VAD-FMK (BD Biosciences, San Jose, CA) was added to the cells after the cells were plated. The inhibition of cell growth was measured by MTT assay and cell counting assay. The assay was repeated three times under the same conditions.

\section{Construction of fascin-small interfering RNA vector and transfection}

In order to construct a vector for fascin-small interfering RNA (siRNA), pSilencer2.1-U6 hygro (Ambion, Inc., Austin, TX) was digested with BglII and HindIII. A chemically synthesized oligonucleotide encoding a fascin-short hairpin siRNA that included a loop motif was inserted downstream of the U6 promoter of the plasmid using a DNA ligation kit (Takara Bio, Inc., Shiga, Japan), and was cloned. Sequences of the oligonucleotide targeted to fascin were 5'-GCCUGAAGAAGAAGCAGAU-3' corre- 
sponding to positions 116 to 134 within fascin exon 1 . An ESCC cell line KYSE170 was stably transfected with either the fascin-siRNA expression vector or the negative control vector (pSilencer2.1-U6 hygro) using FuGene6 reagent (Roche Diagnostics, Basel, Switzerland) [26], and cell clones were selected against $100 \mu \mathrm{g} / \mathrm{mL}$ hygromycin (Nacalai Tesque, Kyoto, Japan).

\section{Tumor formation assay in nude mice}

Suspensions of $1 \times 10^{6} \mathrm{KYSE} 170$ parental (wild) and derivate cells (KYSE 170mock, KYSE 170F3 and KYSE 170F4) in PBS $(60 \mu \mathrm{L})$ were injected subcutaneously into the right flanks of 5-week-old male BALB/c nu/nu mice (Japan SLC, Shizuoka, Japan) at day 0. The inoculation was conducted in five mice per group, and tumor growth was estimated from the average volume of tumors by the formula: $1 / 2 \times \mathrm{L}^{2} \times \mathrm{W}$ (where $\mathrm{L}$ is the length of the tumor and $\mathrm{W}$ is the width of the tumor). At 30 days after injection, all mice were sacrificed and the subcutaneous tumors were resected and fixed in $10 \%$ formaldehyde/ PBS. Tumors were then embedded in paraffin and stained with H\&E and fascin. All animal experiments were performed in accordance with institutional guidelines.

\section{Immunohistochemical staining}

Resected tumors from the in vivo experiments were fixed in $10 \%$ formaldehyde solution, embedded in paraffin, cut in $4 \mu \mathrm{m}$ thick sections, and mounted on aminopropyltriethoxylane-coated glass slides. Immunohistochemical staining was carried out using an Envision Kit (Dako Cytomation, Glostrup, Denmark). Tissue sections were incubated overnight at $4^{\circ} \mathrm{C}$ with anti-human fascin monoclonal antibody clone $55 \mathrm{kDa}$ (DAKO, Osaka, Japan; 1:50 dilution) and then incubated with biotinylated antimouse IgG for 30 minutes at room temperature. Tissue sections were then stained with 3,3' diaminobenzidine liquid system (Dako Cymation, Glostrup, Denmark), counterstained with Mayer's haematoxilyn, dehydrated and mounted. We performed the same protocol using goat anti-human caspase 3 polyclonal antibody (Santa Cruz Biotechnology, CA, USA; dilution 1:500). As a negative control, the primary antibody was replaced with normal mouse IgG, and a further control was carried out without the primary antibody.

\section{TUNEL assay}

The DeadEnd Colorimetric TUNEL system kit was used for the TUNEL assay. The paraffin-embedded tissues were fixed in $4 \%$ formaldehyde with PBS for 15 minutes, permeabilized with $20 \mu \mathrm{g} / \mathrm{ml}$ proteinase $\mathrm{K}$ for 15 minutes and subsequently incubated at $37^{\circ} \mathrm{C}$ for 60 minutes with the rTdT reaction mix on the slide. Streptavidin HRP solution 1:500 in PBS was added and incubated for 30 minutes. DAB solution was then added for 5 minutes.
Then the apoptotic cells were counted in five different fields at $40 \times$, obtaining the average and standard deviation (SD).

\section{Statistical analysis}

The statistical analysis was performed using the software StatView 4.5 (Abacus Concept, Berkley, CA). A p-value of $<0.05$ indicated statistical significance.

\section{Results}

Downregulation of fascin expression by siRNA in ESCC cell lines

The expression of fascin was reduced by $74.8 \%$ in the stable subclones 170F1, $89.1 \%$ in 170F2, 93\% in 170F3 and $97.7 \%$ in $170 \mathrm{~F} 4$. The transfection for the nonspecific siRNA vector (170 mock) did not affect the expression of fascin. HeLa cells were used as a positive control for fascin (Figure 1A). Semiquantitative reverse transcriptionPCR was performed, obtaining similar results to western blot analysis (Figure 1B).

siRNA against fascin decreased cell growth of ESCC in vitro We hypothesized that knockdown of fascin might affect cell growth. In order to verify this hypothesis, we investigated the effect of fascin knockdown on proliferation in one ESCC cell line (KYSE 170). With the suppression of fascin, the cell growth was inhibited by $40.3 \%$ in KYSE

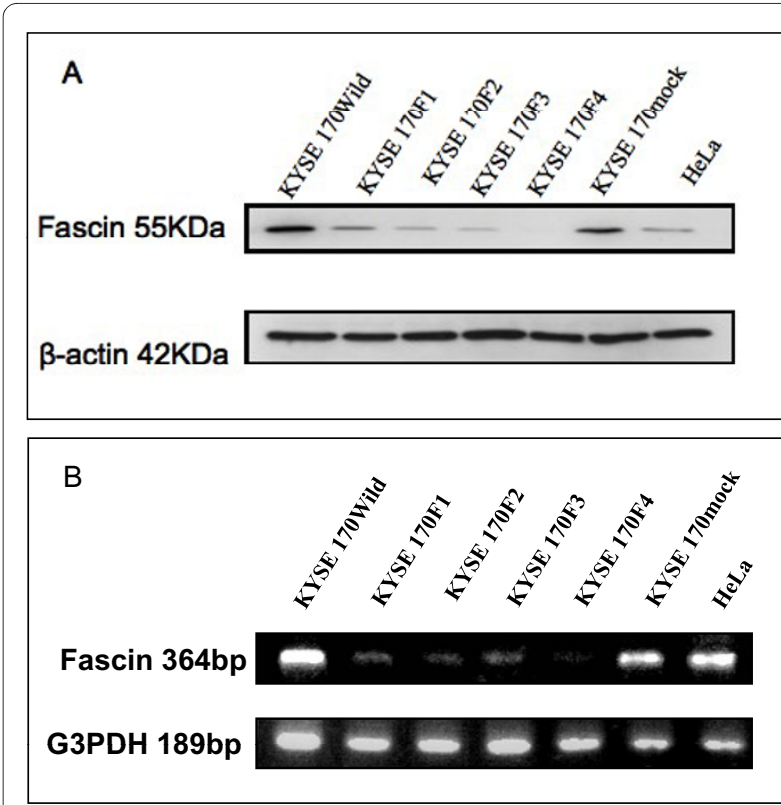

Figure 1 Expression of fascin in parental KYSE cells and stable transfectant with siRNA. (A) Western blot analysis in parental KYSE 170 cells and stable transfectant with siRNA. The HeLa cell line was included as a positive control for fascin expression. (B) Semiquantitative reverse transcription-PCR analysis for fascin expression in parental KYSE 170 cells and stable transfectant with siRNA. The HeLa cell line was included as a positive control in the same analysis. 
70F4 at the day 5, as compared to the empty vector siRNA transfected cell line (KYSE 170 mock) $(\mathrm{p}<0.01)$ (Figure 2).

\section{siRNA against fascin decreased cell adhesion of ESCC in vitro}

In the cell adhesion in vitro experiment, the differences between KYSE 170 mock and fascin knockdown cells were not observed until 6 hours after seeding. The KYSE 170 mock cells attached well after 6 hours, whereas the fascin knockdown cells (KYSE 170F4) did not attach properly and an increasing number of cells was floating. After 24 hours of seeding, the number of adherent living cells was significantly lower in the KYSE 170F4 group than in the KYSE 170 mock group (Figure 3A); in contrast, the number of floating cells increased (Figure 3B). As a result, the total number of cells decreased in the fascin knockdown group. These results suggest that fascin knockdown induces the loss of cell adhesion to the matrix and might result in the inhibition of cell growth in ESCC cells.

\section{Adhesion assay using a general caspase inhibitor (Z-VAD- FMK)}

The general caspase inhibitor (Z-VAD-FMK) did not affect the inhibition of attachment induced by fascin knockdown (Figures 3C and 3D). The difference in cell count at 72 hours between the fascin knockdown cell line and the mock cell line remained the same, both using the general caspase inhibitor and without (mean $40.1 \%$ both). These results provide convincing evidence that detachment may be caused by fascin knockdown.

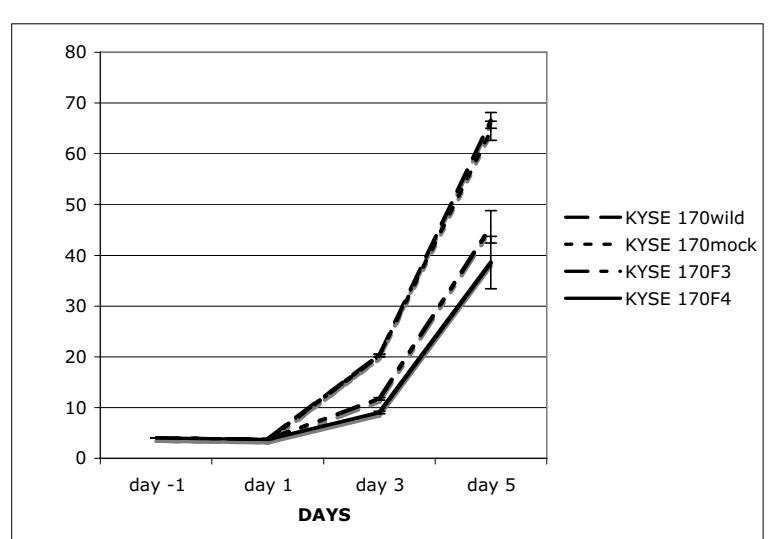

Figure 2 Vector based siRNA for fascin knockdown in the ESCC cell line. In vitro growth assay in KYSE 170 cells and stable transfectant cells with an empty vector (KYSE 170 mock) or fascin-siRNA vector (KYSE 170F3 and KYSE 170F4). The cells were counted every two days and the experiment was performed three times.
Effect of fascin on pFAK and Integrin a2 expression in vitro

Using the in vitro model and western blot analysis, we observed a decreasing expression of the two proteins involved in attachment and cell cycle signaling pFAK and Integrin $\alpha 2$ in all the studied clones, with the highest expression in KYSE 170wild and mock, and the lowest expression in KYSE 170F4 cells (Figure 4). These results suggest that the occurrence of interactions between fascin and other proteins or membrane proteins may occur.

\section{Effect of fascin knockdown on tumor formation in vivo}

In order to investigate the possible effect of fascin-siRNA on tumor formation in vivo, we performed a subcutaneous tumor formation assay in nude mice (Figure 5A). We evaluated tumor volume and weight at 30 days after inoculation. The tumor formations caused by fascin-siRNA transfected cells (KYSE 170F3 and KYSE 170F4) were evidently smaller than those formed by KYSE 170wild and KYSE 170 mock (Figure 5B). The average tumor volume was significantly lower in KYSE 170F3 and KYSE 170F4 by $91 \%$ and $95 \%$, respectively, compared to KYSE 170 mock ( $p<0,0001$ and $p<0,0001$, respectively). The average tumor weight was also inhibited in KYSE 170F3 and KYSE $170 F 4$ by $87 \%$ and $90 \%$, respectively ( $p<0,0004$ and $\mathrm{p}<0,0003$, respectively). Finally, all tumors were stained with $H \& E$ and fascin, and fascin protein expression was reduced to a minimum in tumors of inoculated mice with fascin-siRNA transfected cells, although not in tumors of empty vector transfected cells (KYSE 170 mock) (Figure 6).

\section{siRNA for fascin induced apoptosis of ESCC in vivo}

The analysis of tumoral apoptosis was conducted by TUNEL assay (Figure 7A) and immunohistochemistry for caspase 3 (Figure 7B) where the number of apoptotic cells was higher in the fascin downregulated tumor than in the KYSE 170 mock tumor. For the TUNEL assay, the average of apoptotic cells in the fascin knockdown tumor was 15 \pm 3.6 cells per high power field and for the KYSE 170 mock tumor it was $2 \pm 0.83$ cells per high power field.

\section{Discussion}

Although there are many reports demonstrating the involvement of fascin in carcinogenesis, its biological role and the relationship with the different oncogenic pathways in tumorigenesis is still unclear. In this study, we showed that fascin knockdown strongly inhibits cell growth and cell adhesion abilities of the ESCC cell line KYSE 170 in vitro and in vivo. This is most likely due to focal detachment to the matrix of tumoral cells, suggesting that the occurrence of interactions between fascin and other proteins or membrane proteins may occur. The ability of tumor cells to migrate might be connected to 


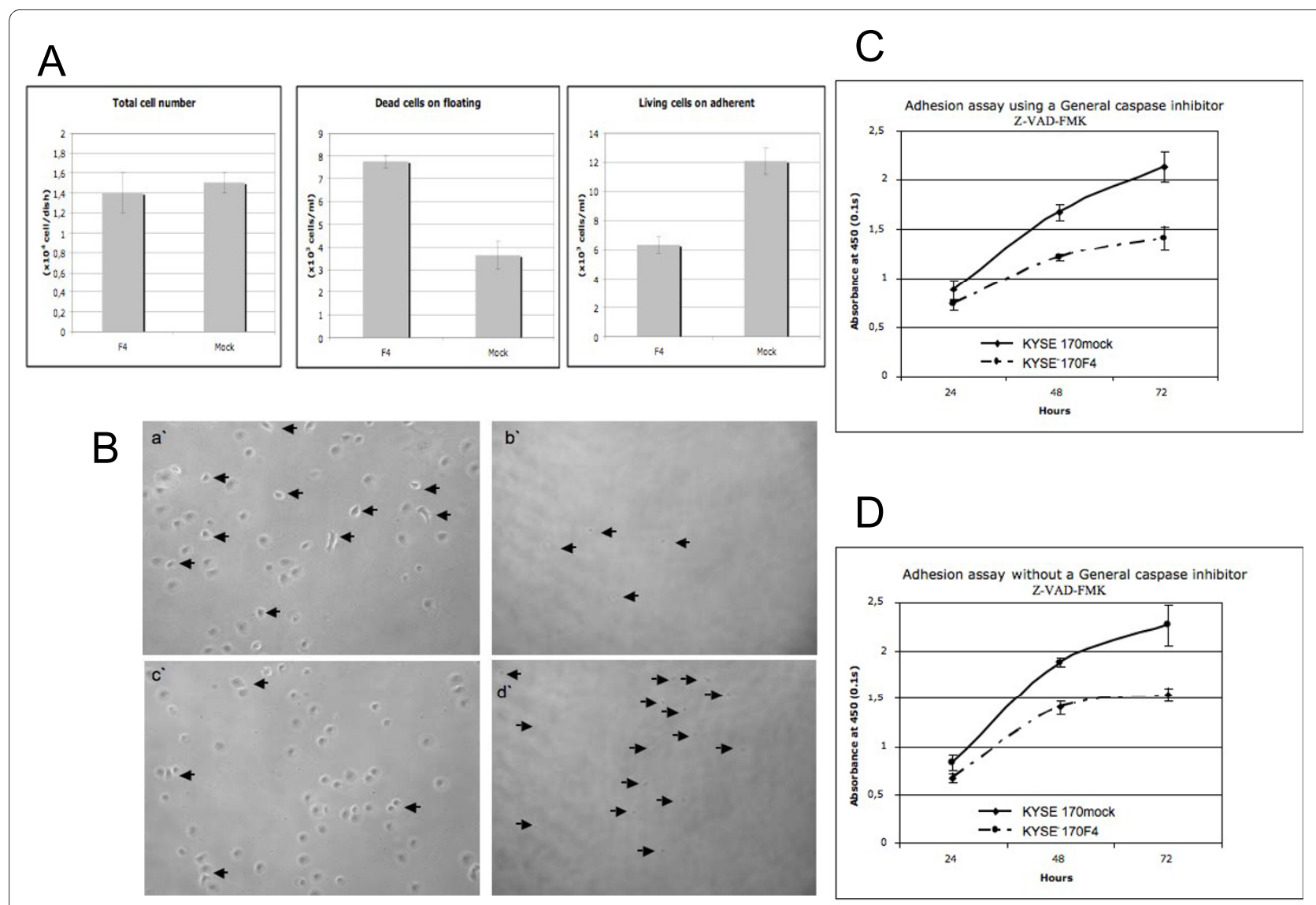

Figure 3 Adhesion assay of stable transfectant cells with an empty vector (KYSE 170 mock) compared to a siRNA vector against fascin (KYSE 170F4). (A) Total number of cells, number of floating dead cells and number of adherent living cells for stable transfectant cells with an empty vector (KYSE 170 mock) as compared to a siRNA vector against fascin (KYSE 170F4). Left, the total number of cells ( $\left.\times 10^{4} \mathrm{cell} / \mathrm{s} / \mathrm{dish}\right)$. Middle, the number of floating dead cells $\left(\times 10^{3} \mathrm{cell} / \mathrm{s} / \mathrm{ml}\right)$. Right, the number of adherent living cells $\left(\times 10^{3} \mathrm{cell} / \mathrm{s} / \mathrm{ml}\right)$. (B) Photographs of ESCC 24 hours after seeding. (a') Adherent stable transfectant cells with an empty vector (KYSE 170 mock). (b') Floating stable transfectant cells with an empty vector (KYSE 170 mock). (c') Adherent stable transfectant cells with a siRNA vector against fascin (KYSE 170F4). (d') Floating stable transfectant cells with a siRNA vector against fascin (KYSE 170F4). (C) Effect of fascin knockdown and the effect of caspase dependency in cell growth. The cells were treated with $200 \mu \mathrm{mol} / \mathrm{L}$ of the general caspase inhibitor Z-VAD-FMK (+). (D) Control, without the general caspase inhibitor Z-VAD-FMK (-).

their tumorigenicity, and fascin might participate in pathways regulating migration, cell growth and detachment-

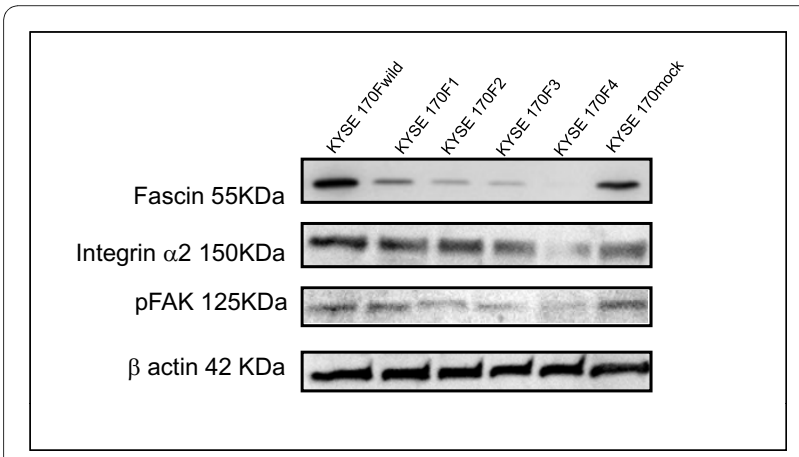

Figure 4 Western blot analysis for the expression of fascin, pFAK and integrin $\alpha 2$ proteins in parental KYSE 170 cells and the stable transfectant with siRNA. induced apoptosis (anoikis) [25,30-32].

The changes involved in cell proliferation might be crucial in regulating tumor growth and progression. In our experimental design, in vitro studies showed that the inhibition of cell growth by fascin knockdown was time dependent, visible evidence in the cell number was not observed until 24 hours after seeding. Furthermore, the caspase general inhibitor did not affect the inhibition of growth caused by fascin knockdown. These results suggest that the inhibition of cell adhesion caused by fascin knockdown results in the inhibition of cell growth. Fascin knockdown cells strongly inhibited tumor growth in vivo. Although this inhibition might be the result of several factors, our data for TUNEL assay and caspase $3 \mathrm{immu}$ nohistochemical staining for the in vivo experiment confirmed that apoptosis was higher in the fascin knockdown cells. The mechanism by which apoptosis is induced by fascin knockdown is unclear. This data sup- 


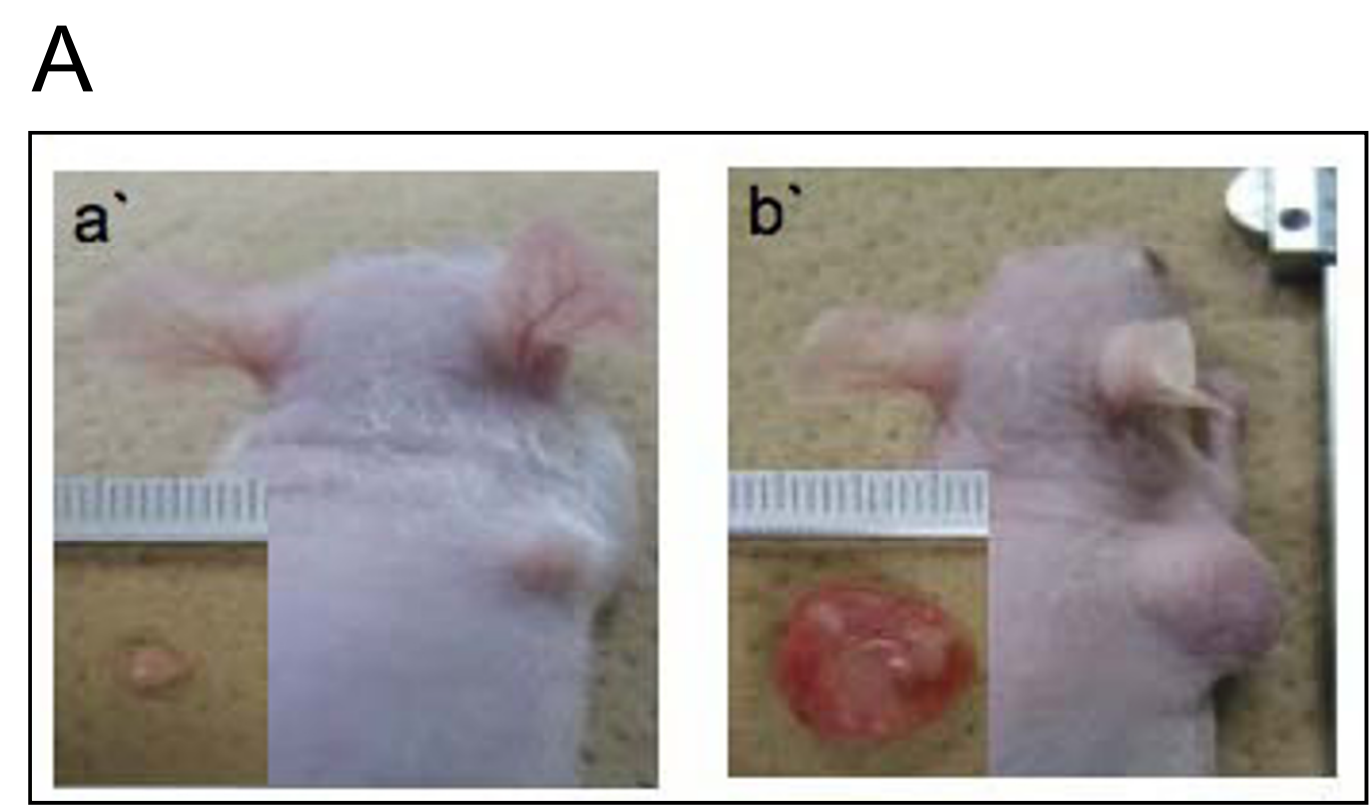

B



Figure 5 The effect of fascin knockdown on tumor formation model. (A) Tumor subcutaneous implantation 30 days after inoculation. (a') Fascin knockdown cells (KYSE 170F4) were injected subcutaneously in the right flank. (b') The KYSE 170 mock cells were injected in the right flank. (B) Tumor growth curves of mice injected with KYSE 170 wild type cells, empty vector-transfected cells (KYSE 170 mock) and fascin siRNA-transfected cells (KYSE 170F3 and KYSE 170F4). 


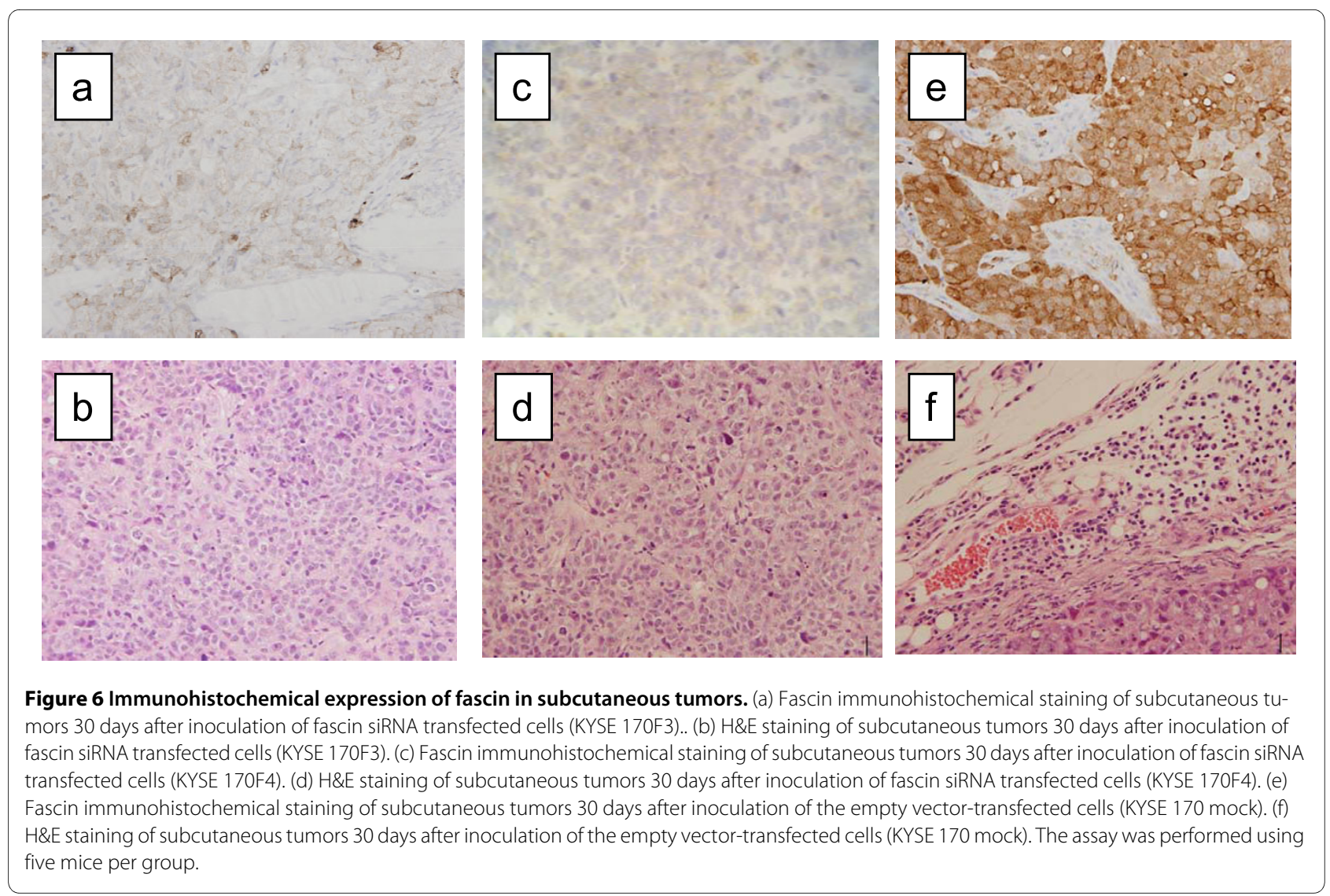

ports our suggestion that detachment might be a cause, rather than a result of apoptosis, resulting in the inhibition of cell growth. However, the results on the in vitro growth assay were rather different compared with the in vivo growth assay, where the inhibition of the cell growth in vitro was lower than in the in vivo study. There are several mechanisms involved in the xenograft model, and the tumor growth is strongly associated with the tumor microenvironment, including the extracellular matrix and cellular components such as fibroblasts, endothelial cells, smooth muscle cells and inflammatory cells (stromal cells) [33,34]. Other reports have demonstrated the mechanism by which fibroblasts promote tumor cells growth in vivo compared with the in vitro model $[35,36]$.

Cell-matrix and cell-cell adhesive interactions play crucial roles in the organization and stability of normal epithelial cells. The conversion of normal cells into malignant cells induces changes in the molecules involved in the adhesion system, which enable a switch to migratory-invasive phenotype in tumor metastasis [37]. These changes are present in ESCC cells, allowing the cells to migrate and invade generating metastasis. The involvement and interaction between fascin and all changes in the membrane are unclear. Malignant tumor cells display a varying degree of resistance to detachment, generating cell-extracellular matrix interactions that are related with the adhesion complex, and this property contributes to tumorigenesis and metastasis [38]. FAK (Focal Adhesine Kynase) is a $125 \mathrm{kDa}$ nonreceptor tyrosine kynase, which regulates cell survival, invasion, migration and cell cycle [39], and its overexpression in human malignant cells has been reported [40-43]. We observed the inhibition of the pFAK by western blot analysis in the KYSE 170 F4 cells. FAK interacts with MAPK cascade regulating cell cycle [44-47]. Furthermore, Integrin $\alpha 2$ is a collagen counter receptor and its knockdown leads to the loss of cell-extracellular matrix adhesion [47]. We observed a considerably low immunoreactivity for integrin $\alpha 2$ through western blot analysis by using the in vitro model. The cell-cellular matrix adhesion is required for the continuous activation of the FAK pathway. Therefore, the mechanism of the inhibition of cell growth by fascin knockdown is likely to be partially due to the decrease in the expression of integrin $\alpha 2$. Further research is necessary in order to understand this mechanism.

Cell adhesion and motility functions must be regulated in a coordinated fashion during tumorigenicity. Fascin interacts strongly with $\beta$-catenin via an extended region that is known to be necessary for interaction between $\beta$ catenin and E-cadherin $[22,30,48,49]$, indicating that fascin and the cytoplasmic domain of E-cadherin compete 
A
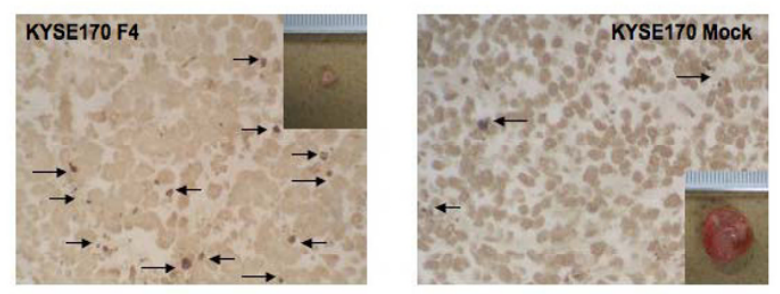

B
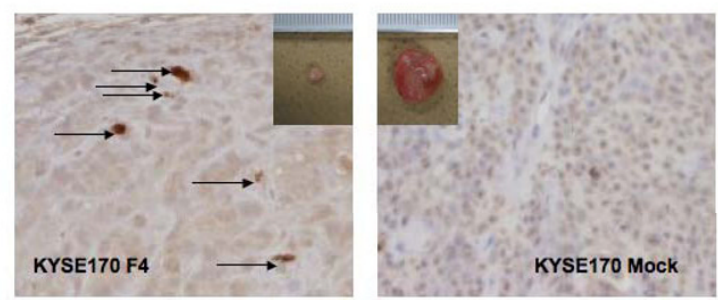

Figure 7 Detection of apoptotic cells in subcutaneous tumors by TUNEL assay and immunohistochemical staining for caspase 3. (A) TUNEL assay detecting apoptotic cells (arrows) using stable transfectant cells with an empty vector (KYSE 170 mock) and with a siRNA vector against fascin (KYSE 170F4). (B) Photomicrographs of immunohistochemical staining detected active caspase 3 pattern (arrows) in the in vivo model tumor using stable transfectant cells with an empty vector (KYSE 170 mock) and with a siRNA vector against fascin (KYSE 170F4).

for the association with $\beta$-catenin. From this perspective, it is still unclear which molecular mechanism underlies the role of fascin in the cadherin-catenin complex system in the regulation of cell proliferation, invasion and cell signaling during tumor progression. We found that $\beta$ catenin expression was higher in the membrane of KYSE $170 \mathrm{~F} 4$ cells in both in vitro and in vivo models, as compared to fascin mock cells, where the expression of $\beta$ catenin was located mainly in the cytoplasm and nuclei (Additional files 1 and 2).

\section{Conclusions}

In conclusion, we have identified a potentially important role of fascin in ESCC, where the knockdown of fascin in an ESCC cell line using a siRNA vector induced several effects on cell adhesion, cell growth and the subsequent survival of the ESCC cell line and decreased tumor formation in vivo. These findings indicate that fascin may play a role in the prevention of further tumor growth and survival. However, further experiments are necessary in order to determine whether fascin contributes to other pathways involved in transformation, cell growth, survival and metastasis.

\section{Additional material}

Additional file $\mathbf{1} \mathrm{Imm}$ unohistochemical staining for $\boldsymbol{\beta}$-catenin. Photomicrographs of immunohistochemical staining detected $\beta$-catenin active pattern in the in vivo model tumor using stable transfectant cells with an empty vector (KYSE 170 mock) and with a siRNA vector against fascin (KYSE 170F4).

Additional file $\mathbf{2}$ Immunofluorescent staining for $\boldsymbol{\beta}$-catenin. Immunofluorescent staining in vitro. KYSE 170 mock cells expressing $\beta$-catenin in the cytoplasm and nucleus (middle); DAPI (right); Actin. (left). KYSE 170 F4 cells expressing $\beta$-catenin in the cytoplasm and membrane (middle); DAPI (right); Actin. (left). Positive control HCT15 cells expressing strongly $\beta$ catenin in the nucleus (middle); DAPI (right); Actin. (left).

\section{Competing interests}

The authors declare that they have no competing interests.

\section{Authors' contributions}

CO carried out protein studies, Tunel analysis, growth assays, immunofluorescence staining, statistical analysis and wrote the manuscript. $\mathrm{TI}$ and $\mathrm{YH}$ designed the fascin-downregulated cells. Al and ST contributed to the study design and participated in the protein studies, adhesion analysis, growth assays, immunofluorescence staining and statistical analysis. YS and SN drafted the manuscript, collected the samples and participated in its design and coordination. FS contributed in the protein studies, apoptosis analysis and manuscript editing, MM contributed to reviewed specimen pathology and manuscript editing. JG and AP contributed to reviewed manuscript editing and reviewed specimen pathology. All authors read and approved the final manuscript.

\section{Acknowledgements}

We cordially thank Ms. Sakiko Shimada for her kind assistance in immunohistochemical staining and providing and culturing the ESCC cell lines; Ms. Kumi Kodama, Ms. Takako Murai and Ms. Akane Iwase for their technical assistance; and Ms. Kati Lindström, Ms. Melanie Trezise and Mr. Alexander Hadjiivanov for their comments on the manuscript. This work was supported in part by a Grant-in-Aid from the Japanese Ministry of Education, Culture, Sports, Science and Technology (Grant N 17390363).

\section{Author Details}

1Department of Pathology, Valencia University, Hospital General Universitario de Valencia, Avenida tres cruces N², CP 46014, Valencia, Spain, 2Department of of Surgery, Sugita Genpaku Memorial Obama Municipal Hospital. 2-2 Ohtecho, Obama, Fukui, 917-8567, Japan, 32Division of Colon and Rectal Surgery, Shizuoka Cancer Center Hospital, 1007 Shimonagakubo, Nagaizumi-cho, Sunto-gun, Shizuoka 411-8777, Japan, 4Department of Surgery, Graduate School of Medicine, Kyoto University, Kawaracho 54 Shogoin, Sakyo-ku, Kyoto, 606-8507, Japan, 5Department of Nanobio Drug Discovery, Graduate School of Pharmaceutical Sciences, Kyoto University, Kawaracho 54 Shogoin, Sakyo-ku, Kyoto, 606-8507, Japan and 6 Department of Surgery \& Science. Graduate School of Medicine \& Pharmaceutical Sciences for Research, University of Toyama, 2630 Sugitani, Toyama, 930-0194, Japan

Received: 30 May 2010 Accepted: 21 June 2010

Published: 21 June 2010

\section{References}

1. Parkin DM, Bray F, Ferlay J, Pisani P: Global cancer statistics, 2002. CA Cancer J Clin 2005, 55:74-108.

2. Visser BC, Venook AP, Patti MG: Adjuvant and neoadjuvant therapy for esophageal cancer: a critical reappraisal. Surg Oncol 2003, 12(1):1-7.

3. Enzinger PC, Mayer RJ: Esophageal cancer. N Engl J Med 2003, 349(23):2241-2252.

4. Aznavoorian S, Murphy AN, Stetler-Stevenson WG, Liotta LA: Molecular aspects of tumor cell invasion and metastasis. Cancer 1993, 71(4):1368-1383. 
5. Partin AW, Schoeniger JS, Mohler JL, Coffey DS: Fourier analysis of cell motility: correlation of motility with metastatic potential. Proc Natl Acad Sci USA 1989, 86(4):1254-1258.

6. Liotta LA, Kohn EC: The microenvironment of the tumour-host interface. Nature 2001, 411(6835):375-379.

7. Otto JJ: Actin-bundling proteins. Curr Opin Cell Bio/ 1994, 6(1):105-109.

8. Tilney LG, Connelly PS, Vranich KA, Shaw MK, Guild GM: Why are two different cross-linkers necessary for actin bundle formation in vivo and what does each cross-link contribute? J Cell Biol 1998, 143(1):121-133.

9. Matsudaira P: Actin crosslinking proteins at the leading edge. Semin Cell Biol 1994, 5(3):165-174.

10. Kureishy N, Sapountzi V, Prag S, Anilkumar N, Adams JC: Fascins, and their roles in cell structure and function. Bioessays 2002, 24(4):350-361.

11. Bryan J, Edwards R, Matsudaira P, Otto J, Wulfkuhle J: Fascin, an echinoid actin-bundling protein, is a homolog of the Drosophila singed gene product. Proc Natl Acad Sci USA 1993, 90(19):9115-9119.

12. Al-Alwan MM, Rowden G, Lee TD, West KA: Fascin is involved in the antigen presentation activity of mature dendritic cells. J/mmuno/ 2001, 166(1):338-345.

13. Cohan CS, Welnhofer EA, Zhao L, Matsumura F, Yamashiro S: Role of the actin bundling protein fascin in growth cone morphogenesis: localization in filopodia and lamellipodia. Cell Motil Cytoskeleton 2001, 48(2):109-120.

14. Mosialos G, Yamashiro S, Baughman RW, Matsudaira P, Vara L, Matsumura $F$, Kieff E, Birkenbach M: Epstein-Barr virus infection induces expression in B lymphocytes of a novel gene encoding an evolutionarily conserved 55-kilodalton actin-bundling protein. J Virol 1994, 68(11):7320-7328.

15. Grothey A, Hashizume R, Ji H, Tubb BE, Patrick CW Jr, Yu D, Mooney EE, McCrea PD: C-erbB-2/HER-2 upregulates fascin, an actin-bundling protein associated with cell motility, in human breast cancer cell lines. Oncogene 2000, 19(42):4864-4875

16. Grothey A, Hashizume R, Sahin AA, McCrea PD: Fascin, an actin-bundling protein associated with cell motility, is upregulated in hormone receptor negative breast cancer. Br J Cancer 2000, 83(7):870-873.

17. Hu W, McCrea PD, Deavers M, Kavanagh JJ, Kudelka AP, Verschraegen CF: Increased expression of fascin, motility associated protein, in cell cultures derived from ovarian cancer and in borderline and carcinomatous ovarian tumors. Clin Exp Metastasis 2000, 18(1):83-88

18. Goncharuk VN, Ross JS, Carlson JA: Actin-binding protein fascin expression in skin neoplasia. J Cutan Pathol 2002, 29(7):430-438.

19. lacobuzio-Donahue CA, Maitra A, Shen-Ong GL, van Heek T, Ashfaq R, Meyer R, Walter K, Berg K, Hollingsworth MA, Cameron JL, Yeo CJ, Kern SE, Goggins M, Hruban RH: Discovery of novel tumor markers of pancreatic cancer using global gene expression technology. Am J Pathol 2002, 160(4):1239-1249

20. Maitra A, lacobuzio-Donahue C, Rahman A, Sohn TA, Argani P, Meyer R, Yeo CJ, Cameron JL, Goggins M, Kern SE, Ashfaq R, Hruban RH, Wilentz RE: Immunohistochemical validation of a novel epithelial and a novel stromal marker of pancreatic ductal adenocarcinoma identified by global expression microarrays: sea urchin fascin homolog and heat shock protein 47. Am J Clin Pathol 2002, 118(1):52-59.

21. Iguchi T, Aishima S, Taketomi A, Nishihara Y, Fujita N, Sanefuji K, Sugimachi K, Yamashita Y, Maehara Y, Tsuneyoshi M: Fascin overexpression is involved in carcinogenesis and prognosis of human intrahepatic cholangiocarcinoma: Immunohistochemical and molecular analysis. Hum Pathol 2009, 402:174-80.

22. Pelosi G, Scarpa A, Puppa G, Veronesi G, Spaggiari L, Pasini F, Maisonneuve $P$, lannucci A, Arrigoni G, Viale G: Alteration of the E-cadherin/betacatenin cell adhesion system is common in pulmonary neuroendocrine tumors and is an independent predictor of lymph node metastasis in atypical carcinoids. Cancer 2005, 103(6):1154-1164.

23. Pelosi G, Pasini F, Fraggetta F, Pastorino U, lannucci A, Maisonneuve P, Arrigoni G, De Manzoni G, Bresaola E, Viale G: Independent value of fascin immunoreactivity for predicting lymph node metastases in typical and atypical pulmonary carcinoids. Lung Cancer 2003, 42(2):203-213.

24. Shimada Y, Maeda M, Watanabe G, Yamasaki S, Komoto I, Kaganoi J, Kan T, Hashimoto Y, Imoto I, Inazawa J, Imamura M: Cell culture in esophageal squamous cell carcinoma and the association with molecular markers. Clin Cancer Res 2003, 9(1):243-249.
25. Zhang H, Xu L, Xiao D, Xie J, Zeng H, Cai W, Niu Y, Yang Z, Shen Z, Li E: Fascin is a potential biomarker for early-stage oesophageal squamous cell carcinoma. J Clin Pathol 2006, 59(9):958-964.

26. Hashimoto $Y$, Ito T, Inoue H, Okumura T, Tanaka E, Tsunoda S, Higashiyama $M$, Watanabe G, Imamura M, Shimada Y: Prognostic significance of fascin overexpression in human esophageal squamous cell carcinoma. Clin Cancer Res 2005, 11(7):2597-2605.

27. Hashimoto Y, Shimada Y, Kawamura J, Yamasaki S, Imamura M: The prognostic relevance of fascin expression in human gastric carcinoma. Oncology 2004, 67(3-4):262-270.

28. Chomczynski P: A reagent for the single-step simultaneous isolation of RNA, DNA and proteins from cell and tissue samples. BioTechniques 1993, 15(3):532-4-536-7

29. Chomczynski P, Sacchi N: Single-step method of RNA isolation by acid guanidinium thiocyanate-phenol-chloroform extraction. Anal Biochem 1987, 162(1):156-159.

30. Tao YS, Edwards RA, Tubb B, Wang S, Bryan J, McCrea PD: beta-Catenin associates with the actin-bundling protein fascin in a noncadherin complex. J Cell Biol 1996, 134(5):1271-1281.

31. Xie JJ, Xu LY, Zhang HH, Cai WJ, Mai RQ, Xie YM, Yang ZM, Niu YD, Shen ZY, Li EM: Role of fascin in the proliferation and invasiveness of esophageal carcinoma cells. Biochem Biophys Res Commun 2005, 337(1):355-362.

32. Valentijn AJ, Zouq N, Gilmore AP: Anoikis. Biochem Soc Trans 2004, 32(Pt3):421-425

33. Chen CY, Chiou SH, Huang CY, Jan Cl, Lin SC, Tsai ML, Lo JF: Distinct population of highly malignant cells in a head and neck squamous cell carcinoma cell line established by xenograft model. J Biomed Sci 2009, 161:100.

34. Kulluri R, Zeisberg M: Fibroblasts in cancer. Nat Rev Cancer 2006, 6:392-401.

35. Ito TK, Ishii G, Chiba H, Ochiai A: The VEGF angiogenic switch of fibroblasts is regulated by MMP-7 from cancer cells. Oncogene 2007, 26:7194-203.

36. Saitoh O, Mitsutake N, Nakayama T, Nagayama Y: Fibroblast-mediated in vivo and in vitro growth promotion of tumorigenic rat thyroid carcinoma cells but not normal Fisher rat thyroid follicular cells. Thyroid 2009, 19:735-42.

37. Jawhari AU, Buda A, Jenkins M, Shehzad K, Sarraf C, Noda M, Farthing MJ, Pignatelli M, Adams JC: Fascin, an actin-bundling protein, modulates colonic epithelial cell invasiveness and differentiation in vitro. $\mathrm{Am} J$ Pathol 2003, 162(1):69-80.

38. Frisch $\mathrm{SM}$, Francis $\mathrm{H}$ : Disruption of epithelial cell-matrix interactions induces apoptosis. J Cell Biol 1994, 124(4):619-626.

39. Sieg DJ, Hauck CR, llic D, Klingbeil CK, Schaefer E, Damsky CH, Schlaepfer DD: FAK integrates growth-factor and integrin signals to promote cell migration. Nat Cell Biol 2000, 2(5):249-256.

40. Owens LV, Xu L, Craven RJ, Dent GA, Weiner TM, Kornberg L, Liu ET, Cance WG: Overexpression of the focal adhesion kinase (p125FAK) in invasive human tumors. Cancer Res 1995, 55(13):2752-2755.

41. Owens LV, Xu L, Dent GA, Yang X, Sturge GC, Craven RJ, Cance WG: Focal adhesion kinase as a marker of invasive potential in differentiated human thyroid cancer. Ann Surg Oncol 1996, 3(1):100-105.

42. Conacci-Sorrell M, Simcha I, Ben-Yedidia T, Blechman J, Savagner P, BenZe'ev A: Autoregulation of E-cadherin expression by cadherin-cadherin interactions: the roles of beta-catenin signaling, Slug, and MAPK. J Cell Biol 2003, 163(4):847-857.

43. Kamarajan $P$, Kapila YL: An altered fibronectin matrix induces anoikis of human squamous cell carcinoma cells by suppressing integrin alpha $v$ levels and phosphorylation of FAK and ERK. Apoptosis 2007, 12(12):2221-2231

44. Li W, Duzgun A, Sumpio BE, Basson MD: Integrin and FAK-mediated MAPK activation is required for cyclic strain mitogenic effects in Caco-2 cells. Am J Physiol Gastrointest Liver Physiol 2001, 280(1):G75-87.

45. Wang Z, Yang H, Tachado SD, Capo-Aponte JE, Bildin VN, Koziel H, Reinach PS: Phosphatase-mediated crosstalk control of ERK and p38 MAPK signaling in corneal epithelial cells. Invest Ophthalmol Vis Sci 2006, 47(12):5267-5275.

46. Horowitz JC, Rogers DS, Sharma V, Vittal R, White ES, Cui Z, Thannickal VJ: Combinatorial activation of FAK and AKT by transforming growth factor-beta1 confers an anoikis-resistant phenotype to myofibroblasts. Cell Signal 2007, 19(4):761-771. 
47. Herzhoff K, Sollberg S, Huerkamp C, Krieg T, Eckes B: Fibroblast expression of collagen integrin receptors alpha 1 beta 1 and alpha2beta 1 is not changed in systemic scleroderma. Br J Dermatol 1999, 141(2):218-223

48. Dolled-Filhart M, McCabe A, Giltnane J, Cregger M, Camp RL, Rimm DL Quantitative in situ analysis of beta-catenin expression in breast cancer shows decreased expression is associated with poor outcome. Cancer Res 2006, 66(10):5487-5494.

49. Conacci-Sorrell M, Zhurinsky J, Ben-Ze'ev A: The cadherin-catenin adhesion system in signaling and cancer. J Clin Invest 2002, 109(8):987-991.

doi: 10.1186/1746-1596-5-41

Cite this article as: Ortiz et al., Effects of small interfering RNAs targeting fascin on human esophageal squamous cell carcinoma cell lines Diagnostic Pathology 2010, 5:41

Submit your next manuscript to BioMed Central and take full advantage of:

- Convenient online submission

- Thorough peer review

- No space constraints or color figure charges

- Immediate publication on acceptance

- Inclusion in PubMed, CAS, Scopus and Google Scholar

- Research which is freely available for redistribution

Submit your manuscript at www.biomedcentral.com/submit
C Biomed Central 